\title{
FIGURA HUMANA OLMECA DE JADE
}

BeATRIZ DE I.A FUENIE

En una colección particular de la ciudad de México, hay una pequena figura humana de jade que se dice procede de Oaxaca (lámina 1) y llama la atención no sólo por la perfección de su talla y su magistral acabado, sino porque la máscara que lleva, guarda un parecido muy cercano con la máscara de serpentina verde proveniente de la región de Pánuco, Veracruz (lámina 2) que forma parte de la colección del Peabody Museum of Archaeology and Ethnology, y uno más lejano con las vasijas-efigie y las urnas con imágenes de Cocijo hechos en Oaxaca clurante la época Monte Albán I.

La figura a que me refiero tiene además otro rasgo que la hace excepcional: llcva en la espalda una inscripción jeroglífica (lámina 3).

No hay certeza en cuanto a la procedencia de esta pequeña escultura, pero a mi parecer, la estructura de su forma, su sisiema de proporción armónica y los símbolos en ella representados la colocan dentro del clásico estilo olmeca. En etecto, sus cortas dimensiones $-6.7 \mathrm{~cm}$. de alto; $2.8 \mathrm{~cm}$. en su parte frontal más ancha y $3.0 \mathrm{~cm}$. en su máximo de profundidad- no alteran el esquema escultórico perteneciente a la más pura tradición de ese estilo.

Se trata de un hombre que se sienta y dobla las piernas en ángulo agudo para apoyar las plantas de los pies en el suelo; los brazos se cruzan hacia el frente descansando sobre las rodillas, que las manos, de cada una de las cuales son visibles cuatro dedos, toman por los lados. La cabeza erguida lleva el rostro cubierto por una máscáa.

Masa compacta en sí, articula rítmicamente los redondeados volúmenes de brazos y piernas con las superficies ahuecadas y hendidas que quedan en el pecho, y entre aquéllos, y entre éstas y los muslos. Cuerpo y piernas fueron tallados como un bloque unitario, de manera tal que los brazos son una suerte de cubierta horizontal que recoge debajo los muslos y las piernas de cilíndrica geometria.

La cabeza, que muestra deformación tubular erecta, es lisa en su vista posterior; un reborde a la altura de la nuca señala el largo del cabello. La máscara, cuya sobreposición al rostro se adviète claramente gracias a la línea en resalte que recone transversalmente la parte media de la cabeza, deja libres las orejas, representadas, de acuerdo con el típico 
esquema olmeca, como dos resaltes verticales angostos y largos. Es en la máscara en donde se concentran, con finura de detalle, los rasgos que otorgan su identidad a la figura (lámina 4).

En su parte central superior se ve un signo formado por una suerte de hoja vegetal, doblada de manera que la mitad inferior del lado derecho se sobrepone a la del lado izquierdo, dejando libres los dos extre. mos. Una doble línea paralela define su contorno, y figura en su parte inferior una $U$ o línea curva con los extremos hacia arriba. Una banda horizontal recoge, en su parte media, el signo antes descrito, bajo el cual, a la altura del entrecejo, se marcaron cuatro resaltes verticales separados por medio de incisiones.

Si se compara este signo con el que lleva la máscara de Veracruz antes mencionada, se verá que es casi exactamente igual a él. De este último, además, se ha dicho que es "un medallón en el mismo estilo que se ve con frecuencia al centro de las vasijas efigie de Monte Albán". ${ }^{1}$ Tal aseveración implica que el signo pasó de Veracruz a Oaxaca o viceversa, y que se incorporó a un sistema de escritura plástica simbólica propio del sobredicho tipo de vasijas de barro. En efecto, recientemente se ha afirmado que durante la fase Monte Albán I, de 500 a 200 a. de C., se encuentran en las vasijas-efigie y en las urnas con representaciones de Cocijo, rasgos propios de las figuraciones olmecas, entre los cuales se mencionan las "bocas felinas", las "cejas de flama", la nariz corta y chata, las placas en el entrecejo y las bandas frontales.2 A las vasijas. efigie o braseros con un rostro enmarcado por tocado y barboquejo, se las ha identificado con un "joven dios del maíz". 3 Anteriormente, se suponía que la imagen representada en tales braseros era la del "joven dios del' fuego". ${ }^{4}$ Todos estos rasgos son, para mí, de dudosa identificación. Son todos, a mi juicio, imprecisos y externos a ese estilo artístico, y no los encuentro con frecuencia ni arraigo en la imaginería de Oaxaca. Su relativa e incierta presencia aparece aislada en unas cuantas piezas.

Ahora bien, considero que el signo que arriba he descrito es considerablemente distinto en forma y significado, en las vasijas-efigie de Monte Albán y en la figura humana de jade y la máscara de Veracruz a que vengo haciendo referencia.

\footnotetext{
1 Easby y Scott, 1970: 108, lám. 70.

2 Scott, 1977 y 1978: 12 a 17.

3 Ibid.: 22.

4 Caso y Bernal, 1952: 390.
} 
En lo que respecta al medallón de las vasijas-efigie, que fue uno de los elementos que determinaron el reconocimiento del "joven dios del maiz" y su supuesta ascendencia olmeca, ha de decirse que se configura con tres partes: la superior que tiene un elemento central lanceolado dirigido hacia arriba, y otros dos laterales curvados en sus extremos hacia direcciones opuestas; la parte media es una suerte de placa encimada cuya forma varía entre el óvalo, el cuadrado, el rombo y el pentágono, y que puede, o no, llevar incisiones en su centro; por último la parte inferior, generalmente rectangular y también con incisiones en su interior. Un remoto parecido de formas con un supuesto símbolo del maíz, característico, según se dice, del dios II del panteón olmeca " . . .señor de la tierra fértil. . y seguramente antecesor de deidades aztecas del maíz como Centéotl", fue el punto de partida para calificar el signo en cuestión como atributo específico del dios del maíz.

Pero ese punto de partida ${ }^{6}$ no es del todo objetivo, y por lo tanto las consecuentes hipótesis no se ven plenamente fundamentadas. ${ }^{7}$ En alguna ocasión, ${ }^{8}$ comenté que el criterio para integrar el diccionario de símbolos olmecas en el Estudio de iconografía olmeca de P. D. Joralemon, era en ciertos aspectos inconsistente; ahora añado que si bien es cierto que tal estudio representó un intento de clasificar y ordenar los signos plásticos olmecas y por ello tiene utilidad, también lo es que no puede ser considerado como definitivo e irrefutable, supuesto que las piezas que sirvieron para formarlo y aventurar interpretaciones de temas y significados, proceden de distintas partes, fueron hechas en diferentes tiempos, en diversos materiales; son, en fin, muestras de varias culturas.

En definitiva, el medallón de los braseros de Oaxaca y los signos que llevan sobre la frente la figura de jade y la máscara de serpentina, son distintos. En aquéllos las formas son torpes e imprecisas; en éstas la línea incisa alcanza la perfección, y los suaves realces un justo equilibrio; en unos y otras es diferente el mensaje comunicado a través de las formas.

Parece conveniente recordar que los símbolos no alteran sustancialmente su forma, si su significado no se modifica por circunstancias

5 Joralemon, 1971: 90.

6 Ibid.

7 Op. cit.

8 De la Fuente, 1972. 
que se gestan en el seno mismo de la cultura que les dio origen o por presiones externas. Coincido con quienes piensan que la civilización de Mesoamérica es única y coherente, pero considero que estuvo integrada por pueblos que vivieron en diversas condiciones culturales, temporales y gecgráficas, y que recibieron, dentro de esa unicidad, sellos distintivos y particulares. Los símbolos usados en el arte de esos pue. blos, pueden si se reiteran en su forma básica en el tiempo y el espacio, comunicar conceptos unitarios; pero si las formas varían y las diferencias de lugar y de época en que se presentan son considerables, lo que transmiten puede, también, ser diferente.

El pueblo que hoy en día llamamos olmeca, habitó la costa del Golfo de México entre 1300 y, acaso, 600 años a. de C. Son fácilmente reconocibles las características principales que rigieron la que fue su más grande expresión artística, la escultura en sus dos modalidades: la monumental en basalto y la de pequeñas dimensiones, en la cual destacan, de manera principal, las fabricadas en jade. Es posible definir, mediante la observación de las esculturas que de ese sitio y de ese tiempo proceden, rasgos inherentes en las cualidades de forma, en el sistema de proporción y en la constancia de elementos figurados. De acuerdo con ellos, la definición del estilo a que pertenecen será más objetiva; pues una escultura sólo se designará legítimamente como olmeca, cuando dicha designación se fundamente en los hechos artísticos de la región de que se trate, y evite contaminaciones al interpretar formas y contenidos.

En Oaxaca, con base en exploraciones arqueológicas, se ha designado como San José Mogote ${ }^{9}$ la fase cultural contemporánea a la de los olmecas de la costa del Golfo. Situada de 1200 a 900 a. C. no hay evidencia en ella de grandes tallas en piedra volcánica ni de miniaturas escultóricas en piedras finas; pero algunos símbolos específicamente olmecas como la Cruz de San Andrés, el diseño "garra-ala" y el elemento $\mathrm{U}$, se encuentran en fragmentos de recipientes de barro. La presencia de estos símbolos, de acuerdo con lo que los estudios arqueológicos comunican, es transitoria, ya que para la fase siguiente, Guadalupe, entre 900 y 700 a de C., 10 se debilita considerablemente, y desaparece para las fases Rosario y Monte Albán I de 700 a 300 a. de C.;1 surgen en

9 Flannery, 1968: 82 a 89.

10 Ibid: 89 a 97 .

11 Marcus, 1976: 125 
cambio una cerámica propia y un estilo artístico en los "danzantes" y las estelas, todos manifestaciones de arte monumental. El desarrollo de este momento en Monte Albán coincide con un vacio cultural en el área olmeca de la costa del Golfo.

Es así como ciertos símbolos aceptados como olmecas, situados fuera de un conjunto estilístico, aparecen en Oaxaca con simultaneidad al auge del arte de la costa; pero no se difunden ni arraigan en la imaginería de esta región, sino que, tras un olvido de cuatro o quinientos años, reaparecen en rasgos y atributos de las efigies de algunos braseros. Así, parece infundada la afirmación de que hay en Oaxaca presencia, influencia y proyección olmecas. El hecho de que allí se hayan encontrado símbolos semejantes a los que al mismo tiempo hacían los olmecas en la costa del Golfo, habla sólo de la fuerza y el impacto cul. tural de éstos; pero los símbolos como tales no se integraron en estilo artístico, por carecer de significado en el vocabulario plástico de los ceramistas y escultores de Oaxaca.

Quiero recordar también, en relación con lo anterior, una discutida urna con representación de Cocijo que data también de la época de Monte Albán I (lámina 5) y que, si bien no comparte rasgos con las vasijas-efigie, tiene semejanza con la figura de jade en que me ocupo y con la máscara de serpentina con la cual la comparo $\mathrm{El}$ parecido de la urna con la máscara, lo vio con claridad, hace años, Miguel Covarrubias; en su conocido cuadro a base de dibujos del desarrollo de la máscara del jaguar olmeca (lámina 6), coloca a dicha urna en una fase de evolución posterior a la de la máscara de serpentina. ${ }^{12}$ La urna es pues, según él, sucesora tardía de la máscara de Veracruz. Tiempo después, P. D. Joralemon, ${ }^{13}$ en su ya mencionado Estudio de iconografia olmeca, toma los dibujos de Covarrubias y les da el mismo valor temático. Es notable la similitud de símbolos en estas piezas, particularmente el del centro de la frente y el de "cejas de flama". Sin embargo, presentan diferencias; en la urna, el primero forma una silueta limitada a los lados por líneas paralelas, curvo en su base con la parte superior ligeramente rehundida; en su centro, se mira una $U$ atravesada por una banda horizontal, recorrida en el interior por una línea ondulante. Se ha sugerido que este signo preciso es antecedente del

12 Covarrubias, 1961 , fig 22

13. Op. cit:; 63. 
glifo $\mathrm{C}$ característico de urnas de Monte Albán de épocas más tardías. ${ }^{14}$ Según Caso, ${ }^{15}$ en un broche que la figura de la urna lleva al centro de su tocado, el glifo $\mathrm{C}$ es la representación de las narices y la boca del tigre.

Además, en la urna el signo forma parte de un diseño simbólico elaborado del cual viene a sẹ sólo el elemento central. Debe por tanto, ser leído dentro del contexto total en que está representado porque es parte de un conjunto; en cambio, en la figura y en la máscara aparece solo, abreviado; es el recurso plástico y simbólico de mayor interés; es el concepto.

Aquí encuentro también una de las manifestaciones primordiales de lo que son y lo que transmiten estos diferentes estilos artísticos. El olmeca, austero en sus formas, preciso en su estructura, perfecto en su proporción, comunica su permanente espiritualidad; el de Oaxaca, sobrecargado de formas, vacilante entre lo curvo y lo recto, pesadamente simétrico, da cuenta de un mensaje transitorio. Se podria pensar que algún alfarero de Oaxaca tuvo en sus manos una imagen semejante a la de la figura de jade o a la de la máscara, y la repitió, sin comprenderla, en el medio y con los recursos a que estaba acostumbrado.

No encuentro en las esculturas olmecas signos idénticos al que he analizado. Pero dos de las Cabezas Colosales, la número 1 de San Lorenzo (lámina 7) y la número 1 de La Venta, llevan en el mismo sitio símbolos similares que deben referirse a la identidad de la imagen re. presentada; la $\mathbf{U}$ es el elemento común entre las colosales esculturas y la máscara y la figura de jade.

Vuelvo al estudio de ésta (lámina 4). En el sitio de las cejas se ven placas con tres picos en la parte superior la inferior es recta y paralela a la línea que delimita por arriba la cavidad orbital; los lados se recortan por líneas curvas. Por encima de las ondulaciones que quedan entre los picos, se ven dos pequeñísimos ovoides dispuestos vertical. mente; su centro superior va hendido. Son iguales a las de la máscara de Veracruz y muy parecidas a las de la urna de Cocijo; su forma, hasta donde yo sé, no se repite en otras representaciones, aunque es posible que se trate de una de las variantes de las "cejas de flama". ${ }^{16}$

Los espacios orbitales de la figura de jade quedan rehundidos bajo

14 Leigh, 1966: 258.

15 Caso, 1928: 29.

$16 \mathrm{Coe}, 1965: 760$ y Joralemon, 1971: 63 . 
el entrecejo proyectado; son amplios y con forma de gancho; las comi. suras internas se cierran en una curva extendida, en tanto que las externas son breves y rectas. Cerca de aquéllas lleva dos perforaciones circulares en lugar de irìs. Excepción hecha de las comisuras externas que descienden considerablemente en la máscara, el resto de los espacios orbitales es igual en ambas imágenes. Aquí la similitud con la urna de Cocijo se pierde enteramente. Sin embargo, la forma de ahuecamiento del espacio orbital y el señalamiento de los discos oculares es, guardando la debida proporción, semejante al que muestra el Monumento 8 de La Venta.

Muy chata y respingona es la breve nariz, de puente ancho y plano y con orificios circulares y exactos. Además de su parecido con la máscara y la urna, constituye un rasgo facial común en la imaginería olmeca. Las mejillas planas y extendidas se adornan en cada lado con una incisión en forma de luna creciente; estas incisiones bajan de las comisuras externas de los ojos, y alcanzan el centro de la mejilla. La máscara y la urna llevan distinta decoración incisa, y diferentes también son en estas últimas las orejas, que se ven más de acuerdo con el dato visual; en la figura repiten el patrón olmeca de las representaciones fantástico-humanas. En la parte baja, la correspondiente al lóbulo, se ven dos perforaciones que la atraviesan.

La boca, entreabierta, es de labios gruesos, precisamente delineados; el superior se ondula en el centro, y el inferior es como una recta banda continua; deja ver los dientes: un agrupamiento central más ancho y dos incisivos laterales que se apuntan hacia abajo. De las comisuras externas de los ojos, y alcanzan el centro de la mejilla. La traste de la humana sensualidad de los labios, que recuerdan los de las Cabezas Colosales 7 de San Lorenzo y 4 de La Venta, con los dientes y colmillos, sin paralelo en los seres del mundo natural. La boca de la máscara difiere de ésta en cuanto que recuerda mejor al labio olmeca vuelto hacia arriba, frecuente en las representaciones fantásticohumanas.

Es en la conformación del cuerpo en donde mejor se reconocen las cualidades escultóricas olmecas: el volumen compacto se reduce a esquemas esenciales, cuya estructura geométrica se suaviza al curvar las superficies y al redondear lo que pudieron haber sido ángulos. Su compacta masa se inscribe dentro de un prisma rectangular; sólida y de apariencia pesada, se equilibra a la perfección en los ritmos plás- 
ticos de las superficies que se rehúnden y de los elementos que se proyectan. De frente y desde arriba, los brazos y antebrazos bordean un cuadrado de centro rehundido que es, a la vez, una suerte de repisa horizontal puesta sobre las piernas separadas por profundo remetimiento. En su vista de perfil, el ritmo se acelera (lámina 8) con el toque de dinamismo plástico que le imprimen las líneas sesgadas que delimitan los muslos; por atrás, la espalda, los amplios hombros y la estrecha cintura, hacen reaparecer, como en los labios y en los muslos, el toque humano y vital, que vence las apariencias meramente geométricas. Es precisamente la excelencia de la talla de la figura humana, con el sabio conocimiento que revela, la cualidad que la incorpora a la clásica escultura olmeca.

Glifos incisos hieren la tersa superficie de la espalda (lámina 9) y una banda realzada ciñe la cintura. Cuerpo, piernas y brazos se mues. tran desnudos en la abstracción de la esencia de sus formas simplísimas; manos y pies se tallaron delicada y minuciosamente, separando cada uno de los dedos por medio de finas incisiones. ${ }^{17}$

En lo que se refiere a los glifos que lleva grabados en la espalda, consulté acerca de su posible lectura a la doctora Joyce Marcus de la University of Michigan; a continuación transcribo traducidos algunos párrafos de la carta de fecha 15 de marzo de este año, en que da respuesta a mi consulta:

Es posible que la escultura corresponda al formativo [o preclásico] medio en fecha, pero dudo que sea una pieza manufacturada en Monte Albán; sin embargo, se le puede haber añadido la inscripción en la espalda después de haber sido importada de otra región. No me gusta especular acerca del significado de los diversos glifos en la espalda, pero podemos comentar algo acerca del estilo y de la morfología de los elementos [...] Se pueden encontrar algunas seme. janzas con esculturas del periodo I de Monte Albán (500-200 a, de C. aprox.). Por ejemplo, [...] la Estela 12 (Caso, 1947, figura 10) y la Estela 15 (Caso, 1947, figura 14). En la parte de arriba tenemos un elemento que se ve como la imagen de una coma en un espejo; este elemento [...] no se presenta, hasta donde yo conozco, en inscripciones zapotecas. Debajo $[.$.$] hay tres circulos alineados verti-$ calmente y dos más a la derecha del cículo más bajo [son cinco círçulos, están dispuestos en forma de escuadra y levan un círculo menor al centro]; es posible que tales círculos sean elementos numéricos, cada cual con el valor de la unidad (1), sin embargo si el 17. Joralemon, 1971: 35 , Joralemon, $1976: 39$ a 42 y Coe, $1973: 6$ 
valor total es 5 (cinco círculos, ¿por qué no emplear la barra? pudieran no ser entonces elementos numéricos o cronológicos, porque no parecen estar modificando un elemento glífico en especial, $v . g$. un día o un mes. El elemento $U$ rectangular [el que se encuentra a la derecha de la coma] es interesante; es parte del ojo de reptil del glifo $M$ de Caso en el cartucho o signo del año en la Estela 12. Debajo del elemento U rectangular, tenemos dos elementos rectangulares atados [dos barras horizontales unidas por otra menor sesgada]; elementos similares aparecen en la Estela 12 y en la Estela $15 . .$.

Del glifo que está bajo las barras horizontales, no me dice nada la doctora Marcus debido a que no era claro en la fotografía que le envié; se trata de dos escuadras o L, opuestas una a la otra y sin que sus extremos se toquen, de manera tal que describen un rectángulo con las esquinas superior izquierda e inferior derecha abiertas. Por mi parte, al revisar las inscripciones de Monte Albän, ${ }^{18}$ no encontré ningún elemento parecido al antes descrito.

Así pues, quedá claro, por ahora, que los gliffos de la figura de jade son ilegibles y tan sólo es posible apuntar algunas semejanzas que guardan con otras inscripciones jeroglíficas de monumentos correspondientes al periodo de Monte Albán I. Me inclino a aceptar la sugerencia de la doctora Marcus en cuanto a que pudieron haber sido añadidos a la escultura después que fue originalmente tallada.

Por razones de estilo, en las cuales incluyo forma y significado, considero que la figura de jade es olmeca; es posible, por lo tanto, que fuera esculpida en tiempos del periodo preclásico medio (o formativo medio para la doctora Marcus). Ahora bien, los olmecas de este periodo usaron signos aislados con significados específicos, pero no se conocen inscripciones jeroglíficas que puedan, con rigor, serles asignados; en cambio, por ese tiempo los habitantes de Oaxaca registraban en forma concreta sus conocimientos acerca de números, calendarios y nombres particulares; hacian uso, en fin, de una sistematizada escritura jeroglifica ${ }^{19}$

Me parece conveniente señalar que la armonía en la estructura de la composición formal de la figura de jade concuerda plenamente con el sistema de proporción que rige buen número de esculturas colosales; de ahí la impresión de su unidad formal. Es evidente una relación de orden entre las partes y la presencia de un patrón matemático de

18 Caso, 1928, 1947 y 1965.

19 Ibid. 
proporción. El sistema usado a este respecto en las representaciones olmecas, el que explica esa impresión visual de justo equilibrio, de armonía de las partes y de la exactitud de los ritmos, es el de la "sección áurea" (lámina 10).

Por su parte, la máscara, como otras imágenes olmecas, se muestra en algún aspecto relevada de las leyes de la realidad visible; figura acaso un ser sobrenatural, que hace concreta y tangible la presencia divina. El hombre, en este caso, es el punto de unión, de encuentro entre el mundo sobrenatural y la naturaleza del mundo terreno.

Me queda por considerar la materia misma de que está hecha la figura: el jade, piedra preciosa, emanó una suerte de fascinación religiosa hacia todos los pueblos de Mesoamérica; en las representaciones pictóricas simboliza el agua, la sangre, el líquido precioso de la vida; en las ofrendas funerarias, figuras y ornamentos de jade acompañan al muerto en su nueva vida.

Muchas son las pequeñas esculturas de este material que provienen de la costa del Golfo; casi todas dan muestra de excelencia como obras de arte. No ocurre lo mismo con las piezas que proceden de Oaxaca. De estas últimas, pocas son las que se han encontrado en contexto arqueológico (cuentas, orejeras, algún pequeño mosaico), ${ }^{20}$ y ciertamente son burdas y torpemente ejecutadas. Es posible que los ol. mecas importaran, como lo hacían con las tierras de colores y con la serpentina, el material en bruto, y que lo labraran y pulimentaran dentro de la tradición de sus propias técnicas.

Consideraciones finales:

1. La estructura de forma y el sistema de proporción armónica de esta figura, o sea el esquema rector de su composición, son análogos a los que definen la escultura monumental y las pequeñas tallas olmecas.

2. Los signos plásticos que le dan identidad (con excepción de la inscripción jeroglífica) son de ascendencia olmeca. Me refiero en especial a los representados en la máscara.

3. No hay, a la fecha, evidencia para hablar de continuidad simbólica entre el arte olmeca de la costa del Golfo y el arte del periodo I de Monte Albán.

20 Caso, 1965: 896. 
DOI: http://dx.doi.org/10.22201/iie.18703062e.1983.52.1186

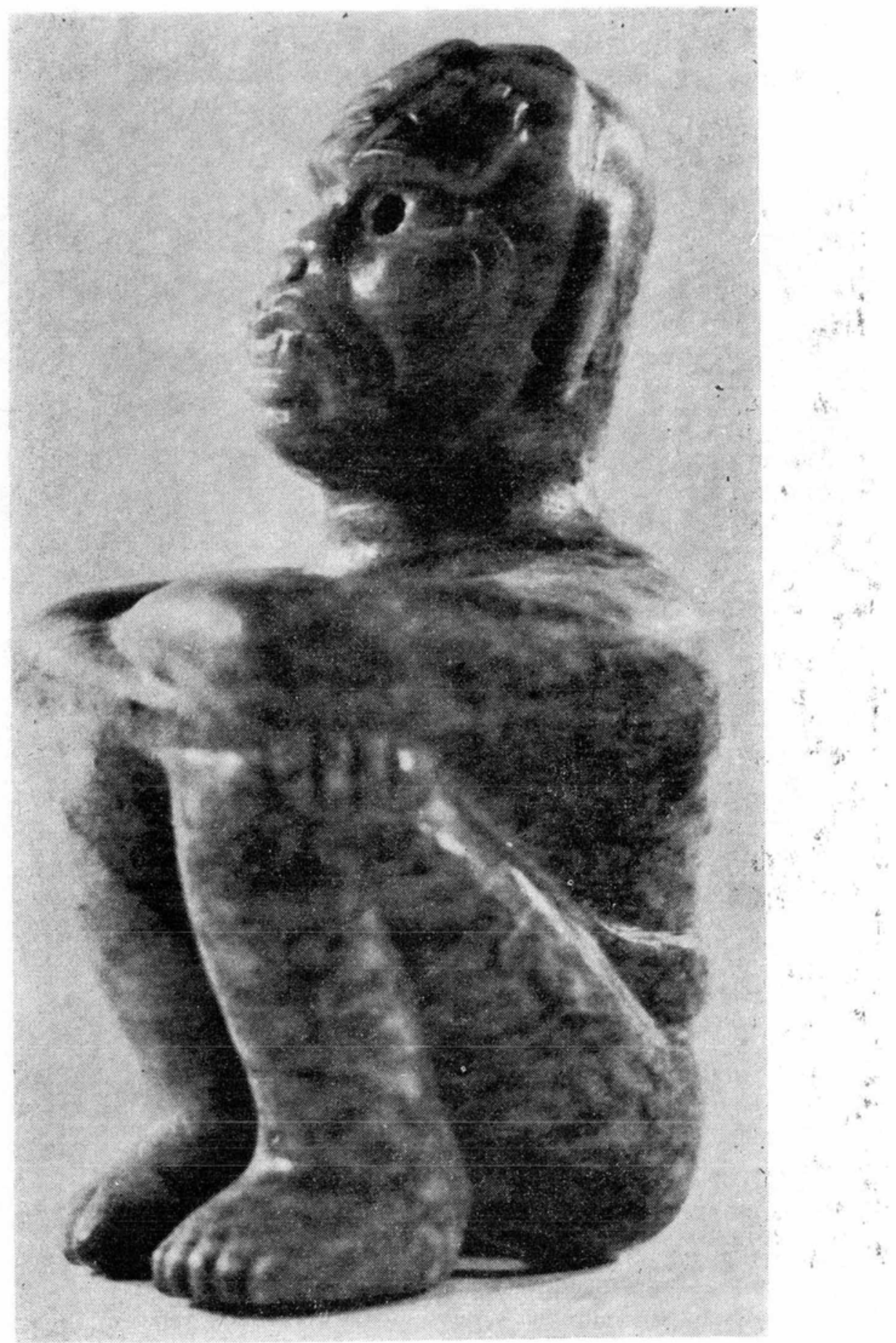

Figura 1. Figura humana de jade. Colección particular. 


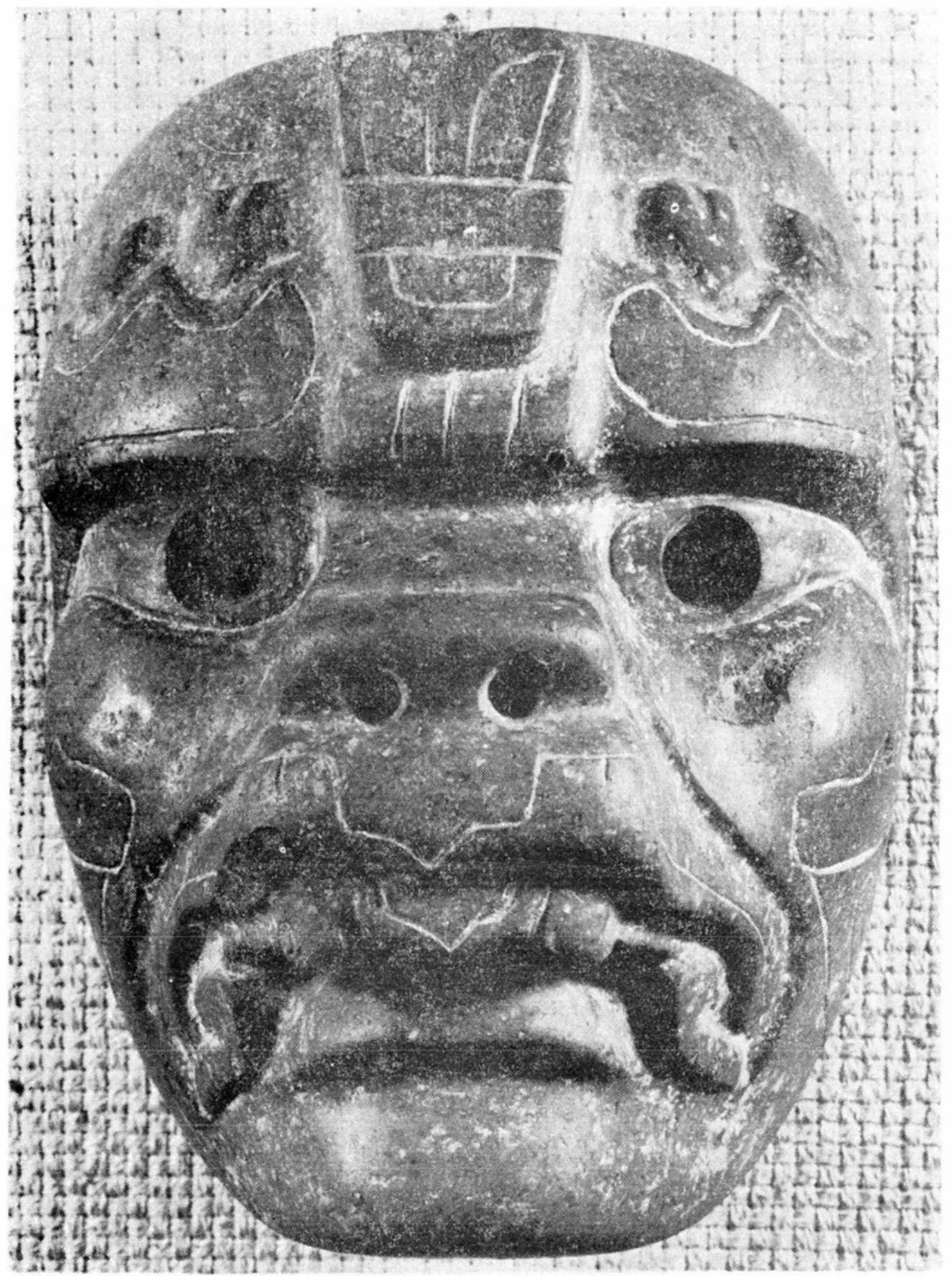

Figura 2. Náscara en serpentina verde, procede de Pánuco, Veracruz. Peabody Miu scum of Archaeology and Ethnology, Harvard University, Máscara Chusets. 
DOI: http://dx.doi.org/10.22201/iie.18703062e.1983.52.1186

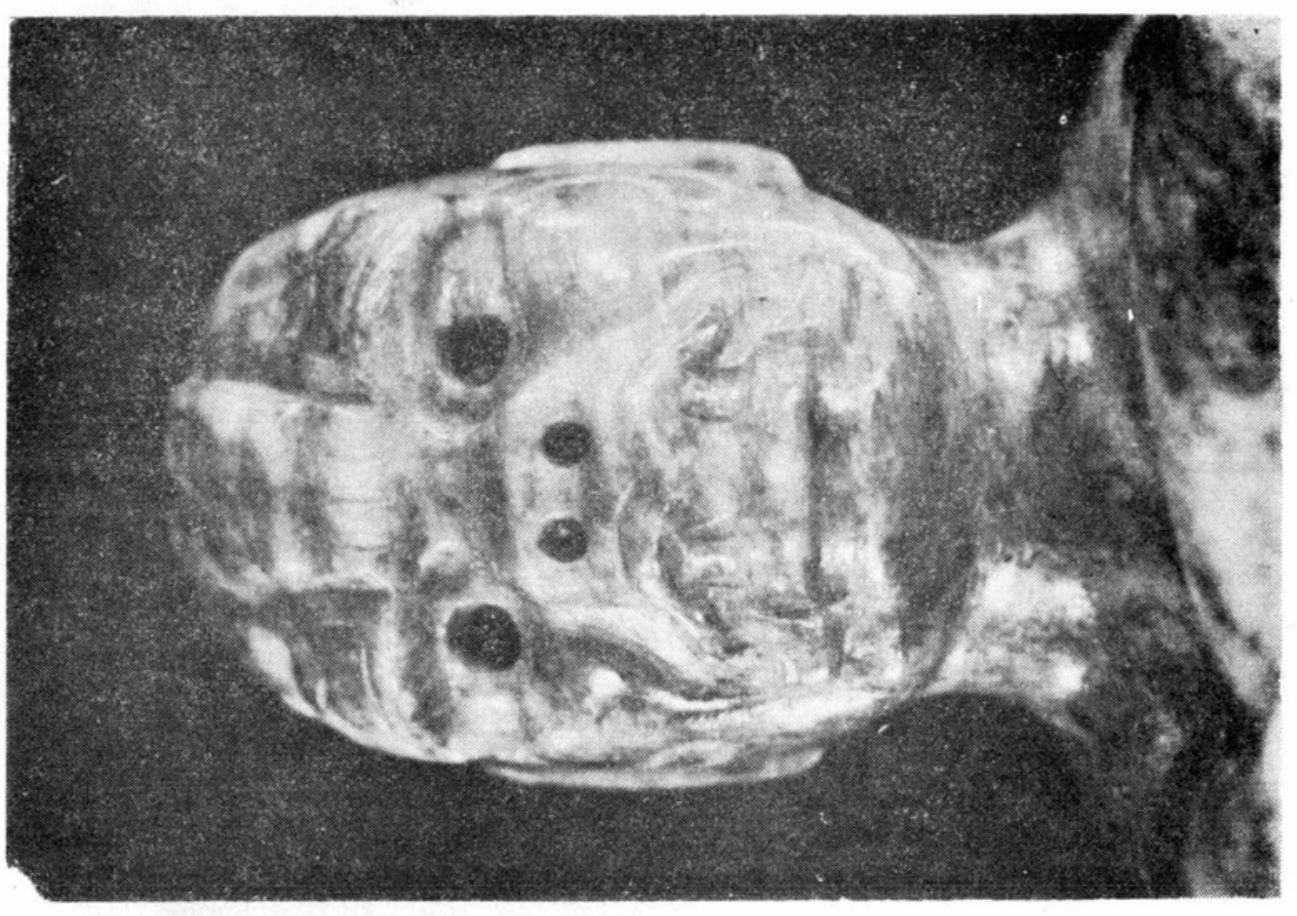

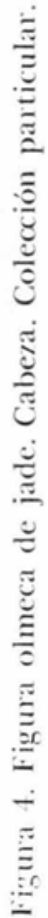

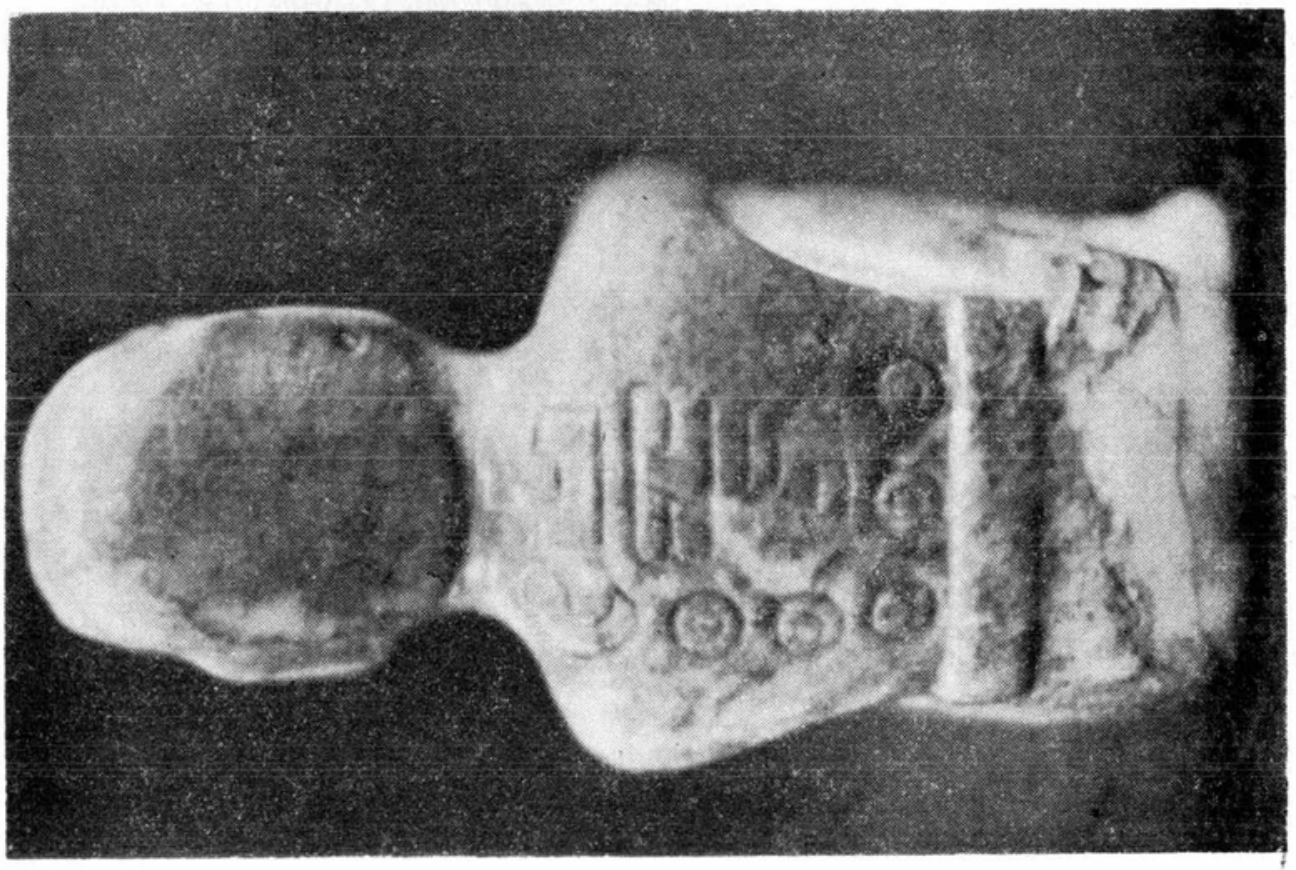

政 
DOI: http://dx.doi.org/10.22201/iie.18703062e.1983.52.1186

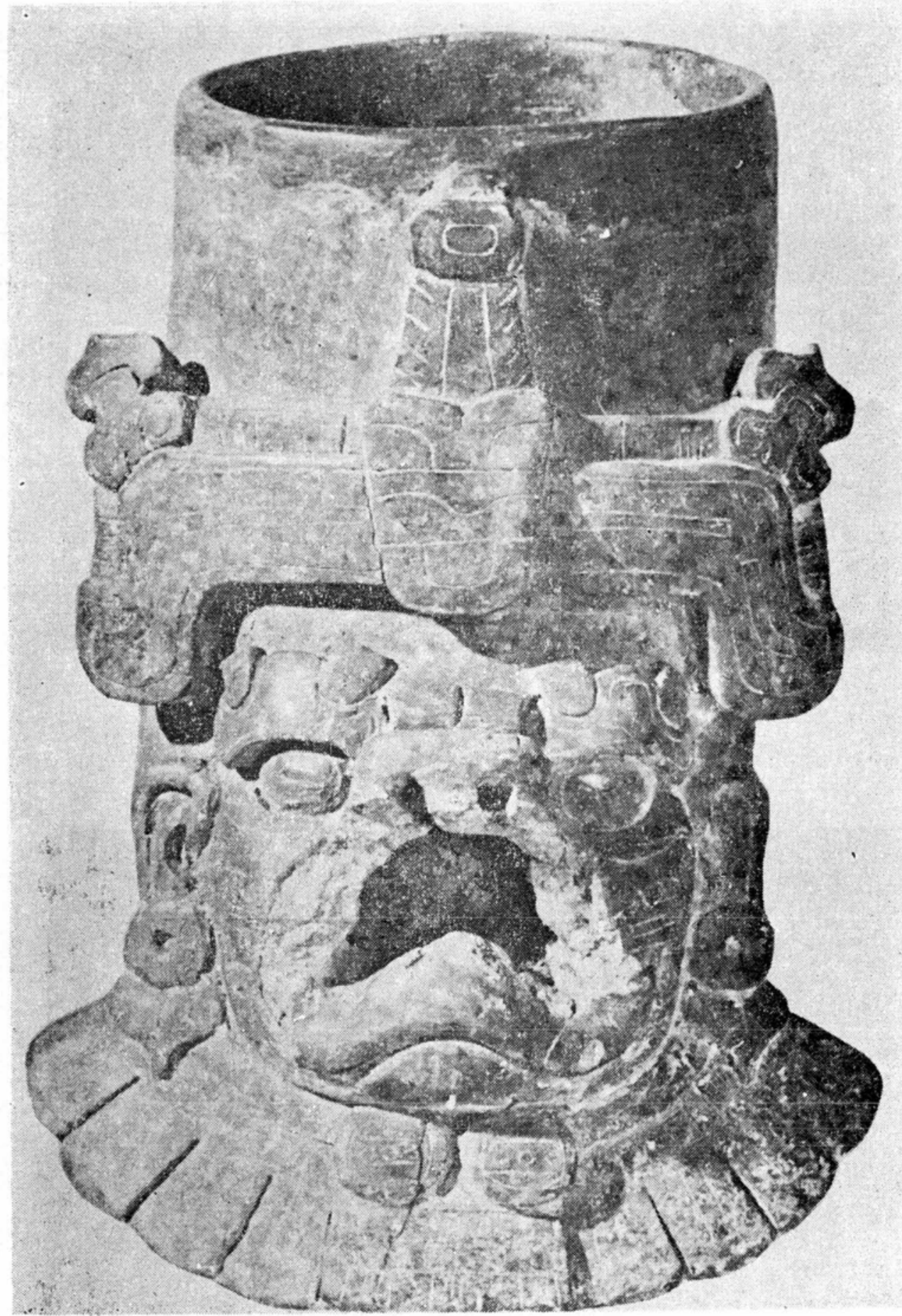

Figura 5. Urna con representación de Cocijo, procede de Oaxaca, Monte Albán I. Museo Nacional de Antropología. 


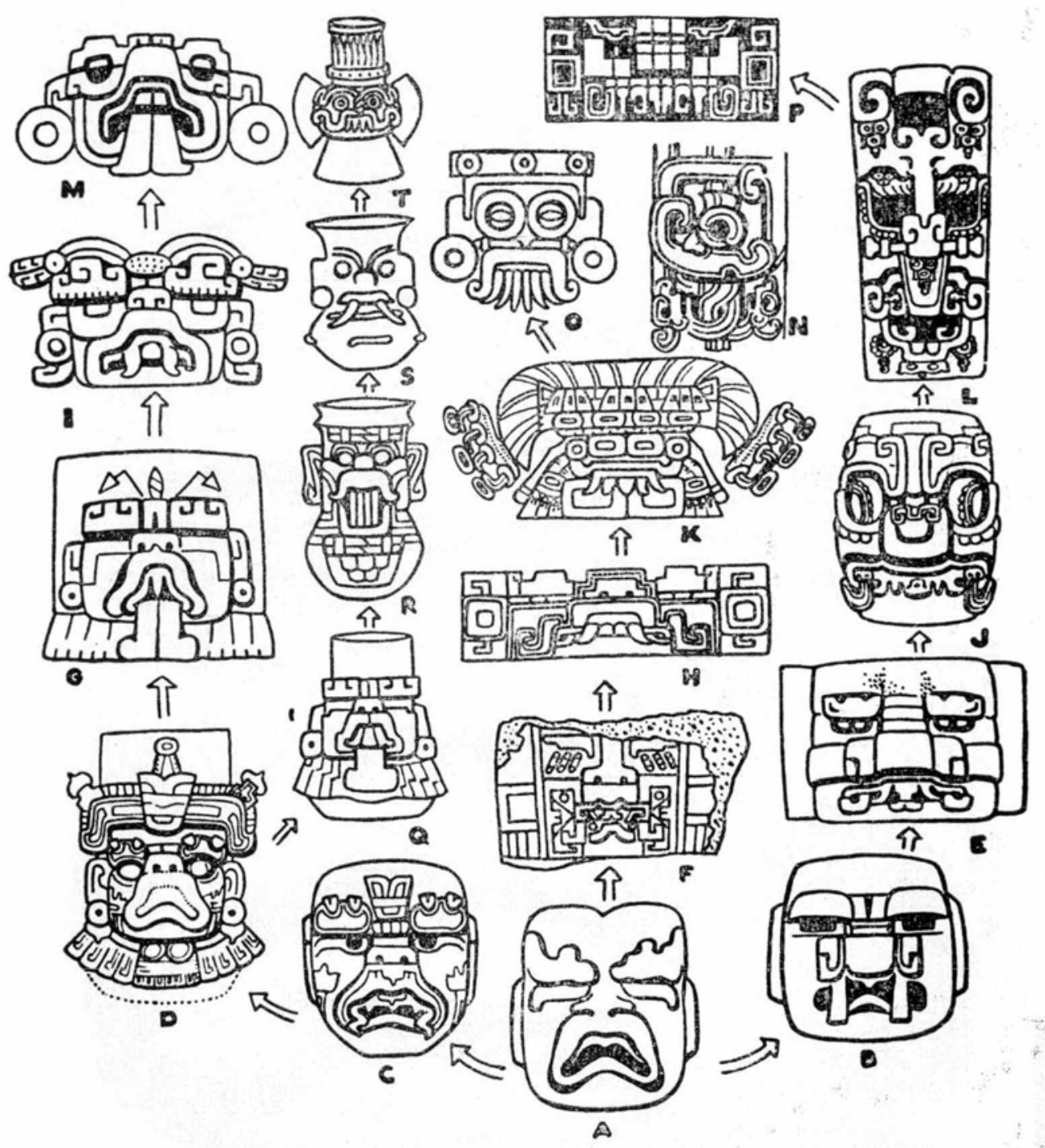

Figura 6. Desarrollo de la máscara olmeca de jaguar. Tomado de Covarrubias 1961, figura 22 . 
DOI: http://dx.doi.org/10.22201/iie.18703062e.1983.52.1186

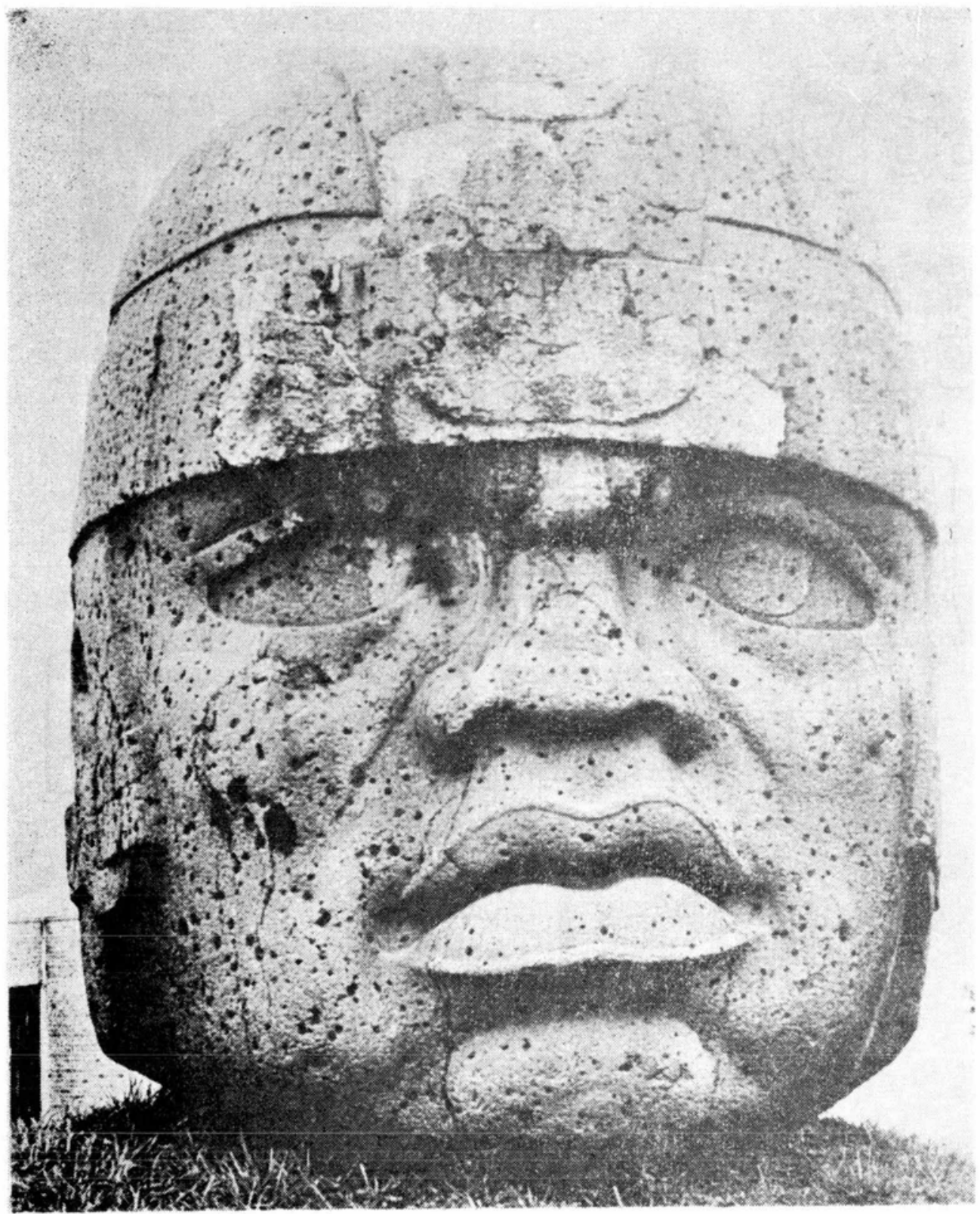

Figura 7. Cabeza l de San Lorenzo, Museo de Antropología de la Universidad de Veracruz, Jalapa. 
DOI: http://dx.doi.org/10.22201/iie.18703062e.1983.52.1186
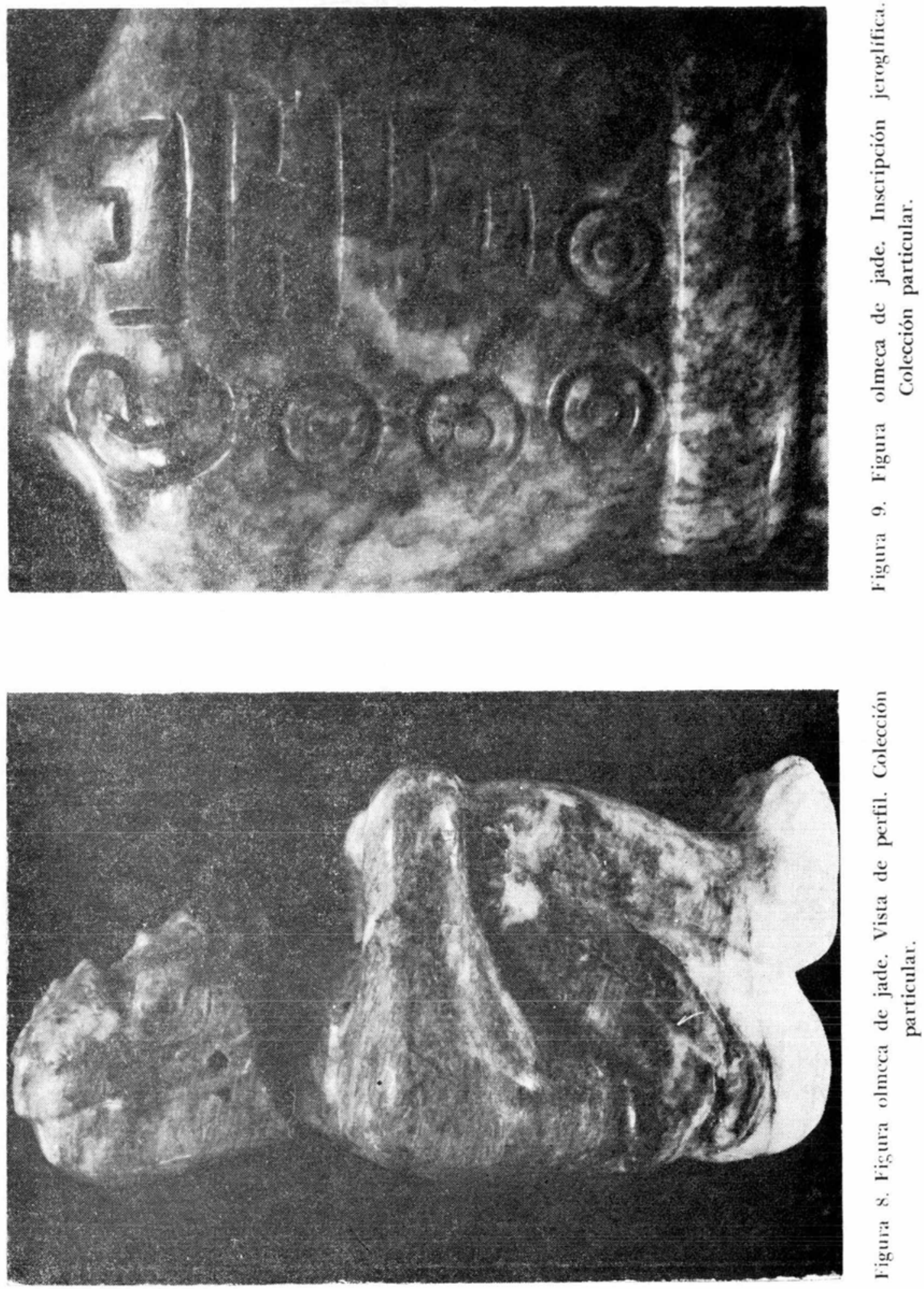
DOI: http://dx.doi.org/10.22201/iie.18703062e.1983.52.1186

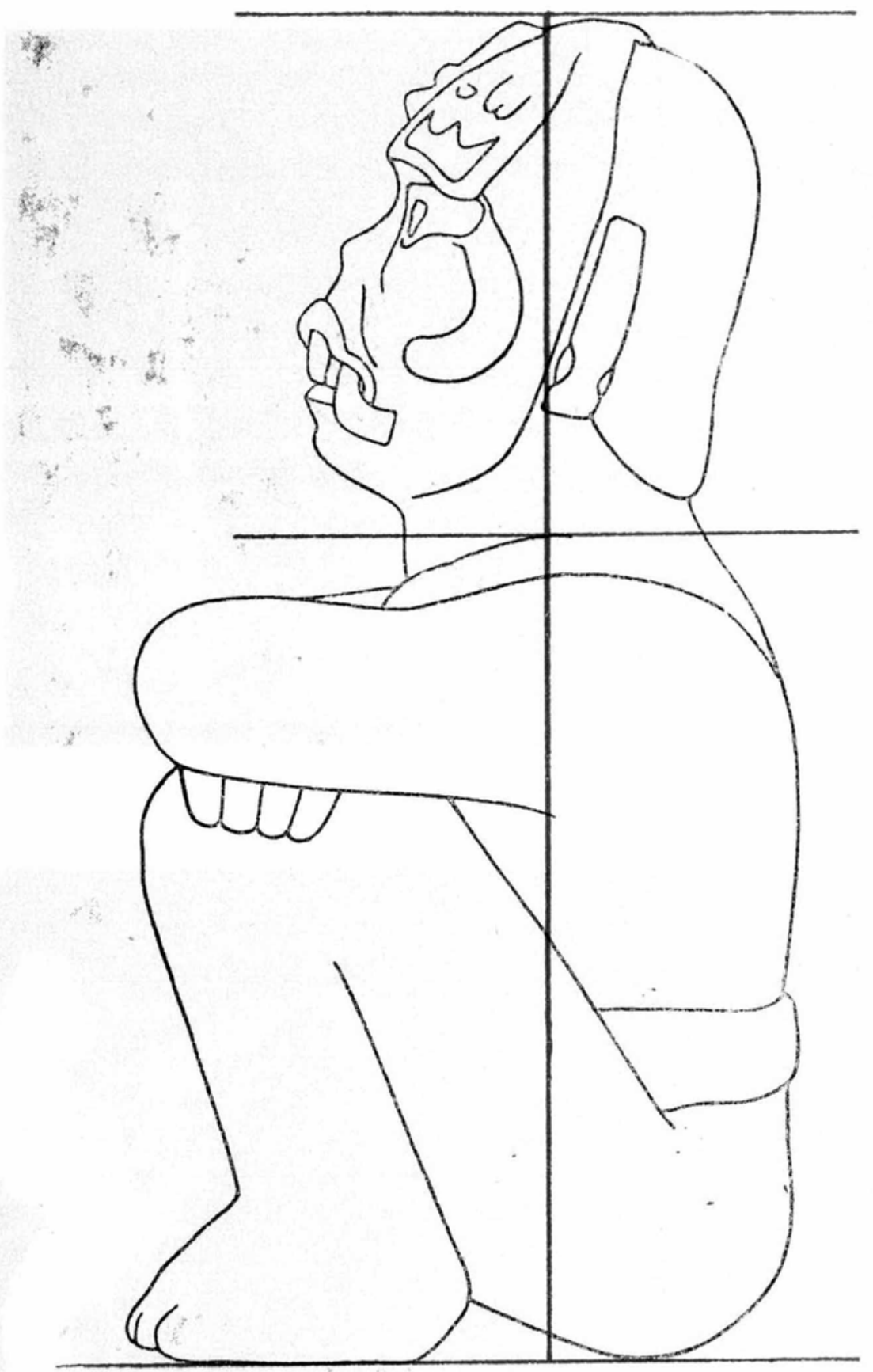

Figura 10. Proporción armónica de figura olmeca de jade. Dibujo. 
4. Los antiguos pobladores de Oaxaca no tallaron el jade con la finura y precisión que lo hicieron los olmecas, ni buscaron expresar en él los mismos significados que éstos.

5. La inscripción jeroglífica no parece haber sido grabada por los olmecas, quienes no tuvieron un sistema de escritura; es posible que fuera añadida en Oaxaca. Por otra parte, el conocimiento de la escritura no hace, por necesidad, que un pueblo sea superior a otro; sólo revela voluntades culturales diferentes.

En resolución: después de haberla analizado, considero que el hecho de hacer destacar la calidad de obra de arte, de esta figura, apoya la posibilidad de afirmar su pertenencia al mundo olmeca. Quizás el acercamiento que con ella he procurado, sea reducido y subjetivo; pero pienso que los recursos que he empleado son los idóneos: parten de lo que la obra misma muestra y la confrontan con otras obras de manera tal que se plantean hipótesis verosímiles en torno a su valor en lo que es y en lo que comunica. 


\section{BIBLIOGRAFÍA}

Bernal, Ignacio,

1968 El mundo olmeca. México, Ed. Porrúa.

Caso, Alfonso.

1928 Las estelas zapotecas. Monografías del Museo Nacional de Arqueología, Historia y Etnografía. México, SEP.

1946 "Calendario y escritura de las antiguas culturas de Monte Albán", en Obras completas (Miguel Othón de Mendizábal). México, vol. I, pp. $113-143$.

1965 a "Lapidary work, goldwork, and copperwork from Oaxaca", en Handbook of Middle American Indians, vol. 3, part two. University of Texas Press, pp. 896-930.

$1965 \mathrm{~b}$ "Zapotec writing and calendar", en Handbook of Middle American Indians, vol. 3, part two. University of Texas Press, pp. 931-961.

Caso Alfonso e Ignacio Bernal.

1952 Urnas de Oaxaca. Memorias del Instituto Nacional de Antropología e Historia. México.

Coe, Michael $\mathbf{D}$.

1968 Americas first civilization. Discovering the Olmec. American Heritage Publishing. Co. Inc., New York.

"The iconology of olmec art", en The Iconography of Middle America Sculpture. The Metropolitan Museum of Art, pp. 1-12

Covarrubias, Miguel.

1961 Arte indigena de México y Centroamérica, la. ed. en español. México, UNAM, p. 68, fig. 22.

De la fuente, Beatriz.

1972 Peter David Joralemon. "A Study of Olmec Iconography". Reseña en Anales del Instituto de Investigaciones Estéticas. México, núm. 41. UNAM, I.I.E., pp. 190-193.

1973 (en colaboración con Nelly Gutiérrez Solana), Escultura monumen. tal olmeca. Catálogo. México, UNAM, I.I.E

1977 Los hombres de piedra. Escultura olmeca México, UNAM, I.I.E.

Easiy, Elizabeth, Kennedy y John F. Scott.

Before Contes: Sculpture of Middle Amevica. New York, The Metropolitan Museum of Art.

Joralmmon, Peter David.

1971 A Study of Olmec Iconography. Studies in Pre-Columbian Art and Archaelogy number seven. Dumbarton Oaks. Trustees for Harward University, Washington, D.C.

1976 "The olmec Dragon. A Study in Pre-Columbian Iconography", en Origins of Religious Art and Iconography in Preclassic Mesoamerica.

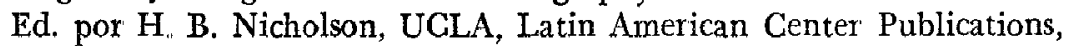
Ethnic Arts Council of Los Angeles pp 27-72. 
Leigh, Haward.

1966 "The Evolution of the Zapotec Glyph C", en Ancient Oaxaca. Stanford, California, Stanford University Press, pp. 245-255.

LUCKERT; KARL M.

1976 Olmec Religion. A Key to Middle America and Begond. Norman, University of Oklahoma Press.

FLANNery, Kent V.

1968 "The olmec and the valley of Oaxaca: a model for inter-regional interaction in formative times", en Dumbarton Oaks Conference on the Olmec. Dumbarton Oaks Research Library and Collection Trustees for Harvard University, Washington, D.C., pp. 79-117.

Marcus, Joyce.

1976 "The Iconography of Militarism at Monte Alban and Neighboring Sites in the Valley of Oaxaca", en Origins of Religious Art and Iconography in Preclassic Mesoamerica. Ed. por H. B. Nicholson, UCLA, Latin American Center Publications, Ethnic Arts Council of Los Angeles, pp. 123-140.

Piña Chán, Román y Luis Covarrubias.

1964 El Pueblo del Jaguar (Los olmecas arqueológicos). Consejo para la planeación e instalación del Museo Nacional de Antropología. México, SEP.

PADDOCK, JoHN.

1966 "Oaxaca in Ancient Mesoamerica", en Ancient Oaxaca Stanford, California, Stanford University Press, pp. 83-240.

ScoTT, Jorn, F.

1977 "Masters and followers: preclassic oaxacan clay sculptores", en Del arte. Homenaje a Justino Fernández. México, UNAM, I.I.E., páginas 20-26.

1978 The Danzantes of Monte Alban. Part I: "Text. Studies in Pre-Columbian Art and Archaeology". Núm. 19, Dumbarton Oaks, Washington, DC., Trustees for Harvard University. 